ALICIA ALMEIDA CANTONI. Asesora de Investigación - IMA

\title{
PERSPECIVAS DE LA SEGURIDAD AÉREA EN EL SIGLO XXI
}

a aviación en el siglo XXI es considerada lo suficientemente segura, pero es evidente el riesgo que existe de verse socavada dicha seguridad ante la creciente ola de siniestros terroristas y de accidentes producidos durante el vuelo y algunos choques en tierra, que traen como resultado la pérdida de valiosísimas vidas y de recursos.

El tema de la seguridad aeronáutica es de constante preocupación a nivel mundial, llevando a que la $\mathrm{OACI}^{1}$ deba asumir el desafío y el compromiso de establecer algunos lineamientos o estrategias que conduzcan al mejoramiento de la misma, yendo más allá de lo contemplado en el marco actual.

El pasado mes de marzo se llevó a cabo un importante evento en el cual se reunieron distintos directores generales de aviación civil para debatir el tema de la seguridad operacional global, siendo de suma importancia la función de la $\mathrm{OACI}$. En una de las ponencias presentadas $^{3}$ se plantearon algunas medidas, a modo de sugerencias, que deben adoptarse en la OACI en relación con los siguientes tópicos: la transparencia y la divulgación de la información sobre seguridad, la aplicación de la estrategia unificada de la OACI, el aumento de la vigilancia de la seguridad operacional y los posibles cambios estructurales en el marco de la seguridad aérea.

${ }^{1} \mathrm{OACI}$. Organización de Aviación Civil Internacional.

${ }^{2}$ Conferencia de Directores Generales de Aviación Civil sobre una Estrategia Mundial para la Seguridad Aeronáutica. Montreal 20-22 de marzo de 2006.

3 Propuestas Para Mejorar La Seguridad Aeronáutica Mundial. (Nota presentada por Austria, en nombre de la Comunidad Europea y de sus Estados miembros, y por los demás Estados miembros de la Conferencia Europea de Aviación Civil (CEAC), así como por EUROCONTROL). Montreal 20-22 de marzo de 2006. 


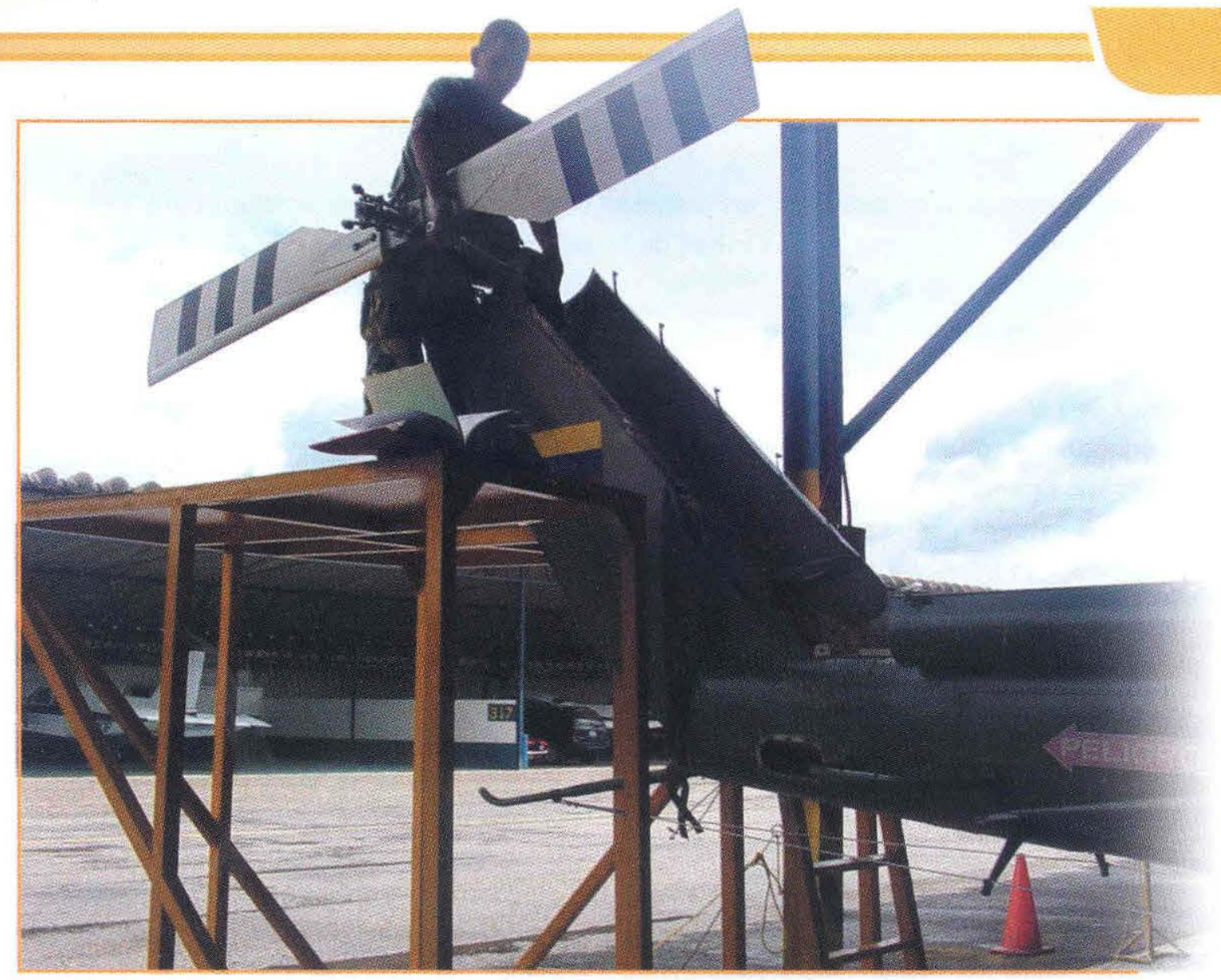

En lo concerniente a la transparencia y divulgación de la información sobre seguridad se expresa que ambas son esenciales para generar un mayor nivel de confianza entre los responsables de la aviación civil internacional. Por tal razón, la OACI debe adoptar medidas distintas a las actuales para mejorar el intercambio de información entre los estados contratantes y para facilitar la vigilancia en el campo de la seguridad operacional, además de dar respuesta a la necesidad de los pasajeros de recibir información oportuna y veraz. Es así que la OACI está en la obligación de comunicar en forma sistemática a todos los estados contratantes los informes elaborados en dicho campo, incluidos los realizados en ciclos anteriores y dar información al público en general basada en los mismos. Estos documentos deben ser claros y contener datos minuciosos relacionados con la seguridad operacional, con el propósito de no perder credibilidad y procurar que todos los estados contratantes puedan emitir juicios sobre la competencia de otros estados en dicha materia. El modelo actual de comunicación de la OACI no es lo suficientemente apropiado, por lo cual debe ser reevaluado, siendo necesario tener una base de datos central a la que todos los estados contratantes tengan acceso. Esta base de datos debe contener información pertinente y la divulgación de ésta debe realizarse en forma ágil y comprensible, haciendo uso de la facultad que le compete según lo establecido en el artículo 55 e) y el artículo 21 del Convenio de Chicago. En este último se establece que los distintos estados contratantes deben recibir y dar información acerca de la matrícula y propiedad de cualquier aeronave empleada habitualmente en la aviación civil internacional. La falta de información completa representa un obstáculo para mejorar la seguridad operacional. Por ello debe analizarse la posibilidad de crear ciertas disposiciones para el empleo de un sistema completo de información sobre procesos de seguridad basado en la cultura de equidad, mediante el cual se facilite la comunicación oportuna de información sobre accidentes e incidentes aéreos, así como las 
recomendaciones publicadas por los distintos organismos de investigación, para, de esta forma, mitigar los riesgos de seguridad de la aviación.

Con respecto a la estrategia unificada para solucionar las falencias en el ámbito de la seguridad operacional, se espera que la OACI cree organizaciones regionales que velen por la vigilancia de la misma, y que promuevan la cooperación tanto regional como subregional, en el área técnica y en los métodos de trabajo, entre otros. Una de las metas para el año 2010 es que se hayan constituido un número significativo de éstas, con los recursos necesarios para funcionar eficaz y competentemente. Se espera, además, que la OACI anime a los estados contratantes a cooperar significativamente tanto a escala bilateral como regional, con miras a cumplir las obligaciones que establece el Convenio de Chicago para los mismos. Esta cooperación debe darse en lo concerniente a recursos humanos, técnicos y financieros de tal forma que se pueda garantizar convenientemente la vigilancia de la seguridad operacional.

En cuanto a la vigilancia de la seguridad operacional se espera que la OACI continúe realizando con éxito las auditorías obligatorias, pero con intervalos de tiempo más cortos y con programas sincronizados para los estados contratantes; revise los métodos del USOAP para determinar los elementos críticos de un sistema de vigilancia de la seguridad operacional, especialmente en lo referente a las listas de control, y notifique las infracciones cometidas al Convenio de Chicago, además de incrementar sus actividades de investigación contempladas en el programa USOAP. Con estas medidas la OACI facilitará la cooperación internacional, la utilización eficaz de los recursos con los que cada estado contratante cuenta y un mejor desempeño de las autoridades de aviación civil.

En el marco de la seguridad operacional para el presente siglo se espera que la OACI se adapte a los cambios tecnológicos que se vienen suscitando en el campo de la aviación y que se revisen los objetivos de la organización así como sus métodos de trabajo, siendo fundamental una reforma de la misma con miras a mejorar su capacidad de reacción y realizando actividades orientadas principalmente a la seguridad operacional, estableciendo normas adecuadas para tal fin. Es importante para ello tomar en cuenta las recomendaciones publicadas por los organismos encargados de investigar los accidentes, e incluir evaluaciones periódicas y sistemáticas de las consecuencias de éstos, así como un procedimiento que permita efectuar consultas rigurosas con el sector y otras partes interesadas. Se debe redactar un nuevo anexo al Convenio de Chicago de carácter específico sobre procesos de seguridad operacional global, donde se incluyan los requisitos sobre la OACI, los recursos, las disposiciones sobre la evaluación y la gestión de la seguridad operacional, así como la cualificación y formación del personal de las autoridades y organismos de aviación encargados de supervisar y vigilar a nivel nacional, regional o subregional.

Las recomendaciones planteadas en la conferencia presentada por Austria son indiscutiblemente de singular importancia, relevancia y pertinencia para garantizar una adecuada seguridad operacional no sólo en los países desarrollados, de quienes viene la propuesta, sino de todos los estados contratantes. La aviación avanza a pasos vertiginosos y la OACI no puede quedar al margen de estos adelantos tecnológicos, su acción debe ser rápida y certera para establecer normas y procedimientos claros que redunden en una mayor seguridad operacional, de tal forma que la seguridad en el siglo XXI sea una realidad incuestionable y las estadísticas de accidentes aéreos no mitiguen la confianza y credibilidad de los pasajeros en la misma. $D$ 